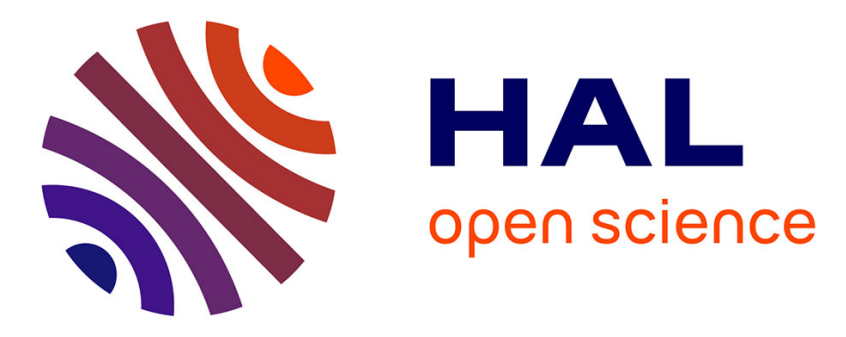

\title{
LC-MS/MS multi-analyte method for mycotoxin determination in food supplements
}

\author{
José Diana Di Mavungu, Sofie Monbaliu, Marie-Louise Scippo, Guy \\ Maghuin-Rogister, Yves-Jacques Schneider, Yvan Larondelle, Alfons \\ Callebaut, Johan Robbens, Carlos van Peteghem, Sarah de Saeger
}

\section{To cite this version:}

José Diana Di Mavungu, Sofie Monbaliu, Marie-Louise Scippo, Guy Maghuin-Rogister, Yves-Jacques Schneider, et al.. LC-MS/MS multi-analyte method for mycotoxin determination in food supplements. Food Additives and Contaminants, 2009, 26 (06), pp.885-895. 10.1080/02652030902774649 . hal00573883

\section{HAL Id: hal-00573883 https://hal.science/hal-00573883}

Submitted on 5 Mar 2011

HAL is a multi-disciplinary open access archive for the deposit and dissemination of scientific research documents, whether they are published or not. The documents may come from teaching and research institutions in France or abroad, or from public or private research centers.
L'archive ouverte pluridisciplinaire HAL, est destinée au dépôt et à la diffusion de documents scientifiques de niveau recherche, publiés ou non, émanant des établissements d'enseignement et de recherche français ou étrangers, des laboratoires publics ou privés. 


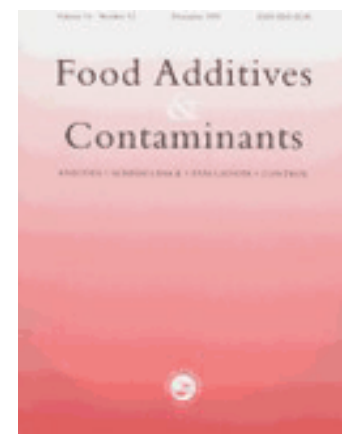

\section{LC-MS/MS multi-analyte method for mycotoxin determination in food supplements}

\begin{tabular}{|r|l|}
\hline Journal: & Food Additives and Contaminants \\
\hline Manuscript ID: & TFAC-2008-393.R1 \\
\hline Manuscript Type: & Original Research Paper \\
\hline Author: & 20-Jan-2009 \\
\hline & $\begin{array}{l}\text { Complete List of Authors: } \\
\text { Sonbaliu, Sofie } \\
\text { Maghuin-rogister, guy } \\
\text { Schneider, Yves-Jacques } \\
\text { Larondelle, Yvan } \\
\text { Callebaut, Alfons } \\
\text { Robbens, Johan } \\
\text { Van Peteghem, Carlos } \\
\text { De Saeger, Sarah }\end{array}$ \\
\hline Methods/Techniques: & Chromatography - LC/MS \\
\hline Additives/Contaminants: & Mycotoxins \\
\hline Food Types: & Dietary supplements \\
\hline & \\
\hline
\end{tabular}

\section{$\diamond$ ScholaroNE \\ Manuscript Central}




\section{Abstract}

A multi-analyte method for the liquid chromatography-tandem mass spectrometric determination of mycotoxins in food supplements is presented. The analytes included A and B trichothecenes (nivalenol, deoxynivalenol, 3-acetyldeoxynivalenol, 15-acetyldeoxynivalenol, neosolaniol, fusarenon-X, diacetoxyscirpenol, HT-2 toxin and T-2 toxin), aflatoxins (aflatoxin- $\mathrm{B}_{1}$, aflatoxin- $\mathrm{B}_{2}$, aflatoxin- $\mathrm{G}_{1}$ and aflatoxin- $\mathrm{G}_{2}$ ), Alternaria toxins (alternariol, alternariol methyl ether and altenuene), fumonisins (fumonisin- $\mathrm{B}_{1}$, fumonisin- $\mathrm{B}_{2}$ and fumonisin- $B_{3}$ ), ochratoxin $A$, zearalenone, beauvericin and sterigmatocystin. Optimization of the simultaneous extraction of these toxins and the sample pre-treatment procedure, as well as method validation were performed on maca (Lepidium meyenii) food supplements. The results indicated that the solvent mixture ethyl acetate/formic acid $(95: 5, v / v)$ was the best compromise for the extraction of the analytes from food supplements. Liquid-liquid partition with $n$-hexane was applied as partial clean-up step to remove excess of co-extracted non-polar components. Further clean-up was performed on Oasis $\mathrm{HLB}^{\mathrm{TM}}$ cartridges. Samples were analysed using an Acquity UPLC system coupled to a Micromass Quattro Micro triple quadrupole mass spectrometer equipped with an electrospray interface operated in the positive ion mode. Limits of detection and quantification were in the range of $0.3-30 \mathrm{ng} / \mathrm{g}$ and $1-100$ $\mathrm{ng} / \mathrm{g}$, respectively. Recovery yields were above $60 \%$ for most of analytes, except for nivalenol, sterigmatocystine and the fumonisins. The method showed good precision and trueness. Analysis of different food supplements such as soy (Glycine max) isoflavones, St John's wort (Hypericum perforatum), garlic (Allium sativum), Ginkgo biloba and black radish (Raphanus niger) demonstrated the general applicability of the method. Due to different matrix effects observed in different food supplement samples, the standard addition approach was applied to perform correct quantitative analysis. In 56 out of 62 samples analyzed none of the 23 mycotoxins investigated was detected. Positive samples contained at least one of the toxins fumonisin- $\mathrm{B}_{1}$, fumonisin- $\mathrm{B}_{2}$, fumonisin- $\mathrm{B}_{3}$ and ochratoxin $\mathrm{A}$.

Keywords: Mycotoxins, multi-target analysis, liquid chromatography, tandem mass spectrometry, food supplements, validation, standard addition 


\section{Introduction}

Mycotoxins are secondary metabolites produced by a wide range of fungi known to contaminate a variety of food and agricultural commodities worldwide (Shephard et al. 1996). Their occurrence in food, beverages and feed has been recognized as potential threat to humans and animals, either by direct contamination of plant materials or products thereof (Fink-Gremmels 1999), or by "carry over" of mycotoxins and their metabolites into animal tissues, milk and eggs after intake of contaminated feed (Galtier 1998; Fink-Gremmels 2008). They are mainly produced by fungi in the Aspergillus, Penicillium, Fusarium and Alternaria genera. Over 400 mycotoxins are known and the foodborne toxins of most interest are aflatoxins, trichothecenes, fumonisins, ochratoxin A (OTA), zearalenone (ZEN) and Alternaria toxins, due to their frequent occurrence and their severe effects on animal and human health (Hussein and Brasel 2001). Reports from the literature indicate that these toxins can also be found in a variety of botanicals (Sewram et al. 2006; Trucksess and Scott 2008).

Numerous botanical products enter markets around the world as food supplements. In the last years, there is a progressive increase of interest in food supplements as they are now consumed more and more. Some are used daily by consumers for various reasons. Raw materials for plant based food supplements can be contaminated with fungi in the field, during harvesting and storage. Indeed, several surveys of toxigenic moulds in botanicals have found high levels of Aspergillus, Penicillium and Fusarium species (Abeywickrama and Bean 1991; Halt 1998; Rizzo et al. 2004). While the presence of mould might not be correlated with the presence of mycotoxins, there are reports of aflatoxins (Rizzo et al. 1999; Tassaneeyakul et al. 2004; Yang et al. 2005; Ali et al. 2005; D'Ovidio et al. 2006; Trucksess et al. 2007), OTA (Thirumala-Devi et al. 2001; Trucksess et al. 2007), ZEN (Gray et al. 2004) and fumonisins (Martins et al. 2001; Omurtag and Yazicioğlu 2004; Sewram et al. 2006) in medicinal plants, tea and other botanicals. Contamination of these raw materials 
could result in the presence of mycotoxins in food supplements, leading to diverse human health problems. It is therefore necessary to have suitable analytical methods for mycotoxin determination in food supplements.

Currently analytical methods used for mycotoxin analysis include thin layer chromatography (TLC) (Betina 1993; Krska et al. 2001), enzyme-linked immunosorbent assay (ELISA) (Ware et al. 1999; Thirumala-Devi et al. 2001; Heber et al. 2001), gas chromatography (GC) with electron capture (Langseth and Rundberget 1998) or mass spectrometric (Schwadorf and Müller 1992; Langseth and Rundberget 1998; Valenta 1998; Shephard 1998; Tanaka et al. 2000; Nielsen and Thrane 2001; Soleas et al. 2001) detection, liquid chromatography with fluorescence detection (LC-FLD) (Valenta 1998; Shephard 1998; Krska and Josephs 2001), and liquid chromatography with tandem mass spectrometry (LC-MS/MS) (Young and Lafontaine 1993; Thakur and Smith 1994; Biselli et al. 2005). LC-MS/MS appears to be most promising as a highly specific, broadly applicable detection method that provides both qualitative and quantitative data. Considering the possible contamination of foodstuffs by several mycotoxin producing fungal species and the production of different types of mycotoxins by one mould, a trend is to develop methods suitable for the determination of several mycotoxins in a single run (Sewram et al. 1999; Monti et al. 2000; Rundberget and Wilkins 2002; Royer et al. 2004; Berthiller et al. 2005; Cavalière et al. 2005; Kokkonen et al. 2005; Sorensen and Elbaek 2005; Abbas et al. 2006; Delmulle et al. 2006; Monbaliu et al.; Sulyok et al. 2006; Spanjer et al. 2008). Currently published protocols, however, have been developed and optimized for different foods and feeds. To the best of our knoweldge, LCMS/MS multi-mycotoxin methods for food supplements have not been published yet. 
The aim of this study was to develop a multi-component analytical methodology, based on LC-MS/MS for the simultaneous determination of an extended list of 23 mycotoxins in food supplements. Target compounds include A and B trichothecenes [nivalenol (NIV), deoxynivalenol (DON), 3-acetyldeoxynivalenol (3-ADON), 15-acetyldeoxynivalenol (15ADON), neosolaniol (NEO), fusarenon-X (F-X), diacetoxyscirpenol (DAS), HT-2 toxin (HT2) and T-2 toxin (T-2)], aflatoxins [aflatoxin- $\mathrm{B}_{1}(\mathrm{AF}-\mathrm{B} 1)$, aflatoxin- $\mathrm{B}_{2}(\mathrm{AF}-\mathrm{B} 2)$, aflatoxin- $\mathrm{G}_{1}$ (AF-G1) and aflatoxin-G $\left.\mathrm{G}_{2}(\mathrm{AF}-\mathrm{G} 2)\right]$, Alternaria toxins [alternariol (AOH), alternariol methyl ether (AME) and altenuene (ALT)], fumonisins [fumonisin- $\mathrm{B}_{1}(\mathrm{~F}-\mathrm{B} 1)$, fumonisin- $\mathrm{B}_{2}(\mathrm{~F}-\mathrm{B} 2)$ and fumonisin-B 3 (F-B3)], OTA, ZEN, beauvericin (BEAU) and sterigmatocystin (STERIG). The method consists of a single step of extraction for all target compounds, considerably simplifying sample preparation. The multi-analyte method was evaluated in terms of precision, linearity, recovery, limits of detection and quantification on maca (Lepidium meyenii) food supplements. The general applicability of the LC-MS/MS conditions as well as the extraction and clean-up procedure was explored with a number of food supplements such as soy (Glycine max) isoflavones, St John's wort (Hypericum perforatum), garlic (Allium sativum), Ginkgo biloba and black radish (Raphanus niger).

\section{Materials and Methods}

\section{Standards}

Mycotoxin standards NIV, DON, 3-ADON, 15-ADON, NEO, F-X, AF-B1, AF-B2, AF-G1, AF-G2, HT-2, AOH, AME, ALT, OTA, ZEN, F-B1, F-B2, BEAU, STERIG as well as the internal standard zearalanone (ZAN) were purchased from Sigma-Aldrich (Bornem, Belgium). DAS and T-2 were purchased from Biopure (Tulln, Austria). F-B3 was obtained from Promec Unit (Tygerberg, South Africa). NIV, NEO and DAS were obtained as solutions $\left(100 \mu \mathrm{g} . \mathrm{mL}^{-1}\right)$ in acetonitrile. From the solid standards, individual stock solutions 


\section{Reagents and materials}

HPLC-grade methanol and acetonitrile as well as $n$-hexane were purchased from VWR International (Zaventem, Belgium). Ethyl acetate, dichloromethane and dimethylformamide were purchased from Acros Organics (Geel, Belgium). A Milli-Q purification system (Millipore, Brussels, Belgium) was used to purify demineralized water. Hydrochloric acid, acetic acid and formic acid from Merck (Darmstadt, Germany) were used. Ammonium acetate was supplied by Grauwmeer (Leuven, Belgium). Trifluoroacetic acid was from Fluka (Buch, Zwitserland). The cartridges used for solid phase extraction (SPE) were Oasis HLB ${ }^{\mathrm{TM}}$ (200 mg, $6 \mathrm{~mL}$ ) from Waters (Milford, MA, USA). Other cartridges tested were Carbograph from LARA (Rome, Italy) and Bakerbond aminopropyl $\left(\mathrm{NH}_{2}\right)$ from Achrom (Zulte, Belgium). 


\author{
Ultrafree $^{\circledR}$-MC centrifugal filter devices $(0.22 \mu \mathrm{m})$ from Millipore (Bedford, MA, USA) were \\ used.
}

\title{
Samples
}

The 62 samples analysed consisted of different maca (Lepidium meyenii), soy (Glycine max) isoflavones, St John's wort (Hypericum perforatum), garlic (Allium sativum), Ginkgo biloba and black radish (Raphanus niger) based food supplements. These food supplements were obtained commercially from drugstores, specialized shops or through the internet. Capsules (dried products and oils) were opened and the content was released and homogenised before use according to the sample preparation procedure. Tablets were ground to obtain a fine and homogenised powder prior to the extraction step.

\begin{abstract}
Method optimization and method validation were performed using commercial food supplement samples purchased from drugstore and which were tested free from mycotoxins. The absence of mycotoxins was confirmed as follows: a portion of sample was analyzed as such and another portion was spiked with the target analytes prior to analysis. By comparing with a solution of standards, no peaks corresponding to the target analytes were found in the non-spiked sample, whereas they were found in the spiked sample.
\end{abstract}

\section{Sample preparation}

One gram of sample was extracted with $25 \mathrm{~mL}$ ethyl acetate/formic acid $(95: 5, v / v)$ during 30 minutes on an Agitelec overhead shaker (J. Toulemonde \& Cie, Paris, France). The sample extract was centrifuged and $20 \mathrm{~mL}$ of the extract was evaporated until dryness. For defatting, the residue was reconstituted in $5 \mathrm{~mL}$ of methanol/water $(50: 50, v / v)$ and $10 \mathrm{~mL}$ of $n$-hexane 
were added. The mixture was shaken and centrifuged. The aqueous fraction was transferred into a test tube using a pasteur pipette. Fresh solutions (2 times $5 \mathrm{~mL}$ ) of methanol/water $(50: 50, v / v)$ were added to the hexane fraction and the procedure was repeated as mentioned above. After evaporation of the combined aqueous fraction, the residue was reconstituted in $400 \mu \mathrm{L}$ methanol/water $(50: 50, v / v)$ and centrifuged in a Ultrafree ${ }^{\circledR}-\mathrm{MC}$ centrifugal device for $10 \mathrm{~min}$ at $14000 \mathrm{~g}$. Afterwards, a $250-\mu \mathrm{L}$ aliquot of the filtrate was diluted to $25 \mathrm{~mL}$ with water. The obtained solution was further cleaned-up using Oasis HLB ${ }^{\mathrm{TM}}$ SPE cartridges. Firstly, the SPE cartridges were conditioned with $10 \mathrm{~mL}$ of dichloromethane/methanol (80:20, $v / v$ ) containing $50 \mathrm{mM}$ formic acid, followed by $5 \mathrm{~mL}$ methanol, $20 \mathrm{~mL}$ acidified water (10 $\mathrm{mM}$ hydrochloric acid in water) and finally $10 \mathrm{~mL}$ water. After the conditioning step, the sample extract was quantitatively brought onto the SPE cartridge, which was then washed by passing $10 \mathrm{~mL}$ of water. Elution of mycotoxins was performed by passing consecutively $1 \mathrm{~mL}$ methanol and $4 \mathrm{~mL}$ dichloromethane/methanol $(80: 20, v / v)$ containing $50 \mathrm{mM}$ formic acid. The eluate was evaporated under a gentle stream of nitrogen and reconstituted with $100 \mu \mathrm{L}$ of injection solvent, which consisted of methanol/water/acetic acid (57.2:41.8:1, $v / v / v)$ containing $5 \mathrm{mM}$ ammonium acetate. The resulting solution was centrifuged in a Ultrafree ${ }^{\circledR}-$ MC centrifugal device for $10 \mathrm{~min}$ at $14000 \mathrm{~g}$ prior to LC-MS/MS analysis.

\section{LC-MS/MS analysis}

The LC-MS/MS system consisted of a Waters Acquity UPLC apparatus coupled to a Micromass Quattro Micro triple quadrupole mass spectrometer (Waters, Milford, MA, USA) equipped with a Z-spray electrospray ionization (ESI) interface. The analytical conditions were as previously described (Monbaliu et al. 2009) and are summarized beneath. Chromatographic separation was achieved using a Symmetry $C_{18}$ column $(5 \mu \mathrm{m}, 150 \times 2.1$ mm i.d.) with a Sentry guard column $(3.5 \mu \mathrm{m}, 10 \times 2.1 \mathrm{~mm}$ i.d.) both supplied by Waters 
(Zellik, Belgium). The column was kept at room temperature. A mobile phase consisting of eluents A [water/methanol/acetic acid $(94: 5: 1, v / v / v)$ containing $5 \mathrm{mM}$ ammonium acetate] and $\mathrm{B}$ [methanol/water/acetic acid $(97: 2: 1, v / v / v)$ containing $5 \mathrm{mM}$ ammonium acetate] was used at a flow rate of $0.3 \mathrm{~mL} \cdot \mathrm{min}^{-1}$. A gradient elution was applied as follows: $0-7 \mathrm{~min}, 95 \%$ A / 5\% B - 35\% A / 65\% B; 7-11 min, 35\% A / 65\% B - 25\% A / 75\%B; 11-13 min, 25\% A / 75\% B - 0\% A / 100\% B; 13-15 min, 0\% A / 100\% B; 15-16 min, 0\% A / 100\% B - 40\% A / 60\% B; 16-22 min, 40\% A / 60\% B - 60\% A / 40\% B; 22-23 min, 60\% A / 40\% B -95\% A / 5\% B; 23-25 min 95\% A / 5\% B. The injection volume was $20 \mu \mathrm{L}$.

The mass spectrometer was operated in the positive electrospray ionization (ESI+) mode. MS parameters for the analysis were as follows: ESI source block and desolvation temperatures: $150{ }^{\circ} \mathrm{C}$ and $350{ }^{\circ} \mathrm{C}$, respectively; capillary voltage: $3.2 \mathrm{kV}$; argon collision gas: $4.12 \times 10^{-3}$ mbar; cone nitrogen and desolvation gas flows: 20 and $500 \mathrm{~L} \cdot \mathrm{h}^{-1}$, respectively. In order to identify the target mycotoxins in the food supplement samples, a diagnostic MS "fingerprint" was built up firstly based on the MS spectra of solutions of standards. After selection of the precursor ions for each analyte, product ions were obtained with a combination of cone voltages and collision energies, parameters that were previously optimized. For increased sensitivity and selectivity, data acquistion was performed working in multiple reaction monitoring (MRM) mode. For part of the mycotoxins investigated, more than two MRMtransitions were initially monitored. The two transitions that resulted in higher sensitivity and better selectivity were selected in the final method. MRM transitions, the optimum cone voltages and collision energies selected for each transition are given in Table 1, as well as the indicative retention times on the column. The first transition, which corresponds to the most abundant product ion was used for quantification, and the second one for confirmation purposes. Masslynx and Quanlynx software (Micromass, Manchester, UK) was used for data acquistion and processing. 


\section{Standard addition technique}

When mycotoxin concentrations had to be confirmed in suspect positive samples, the standard addition approach was applied. Each sample was divided into four portions. One portion was analysed as such, whereas the other three portions were spiked prior to analysis with the target analytes at increasing levels of concentrations, corresponding to 2, 3 and 4-folds the initial level, which was previously assessed by external standard. All four fractions were submitted to the sample preparation procedure as described under section 2.4 , and the internal standard was added before determination by LC-MS/MS. The ratios of the peak areas of the target analytes and the internal standard were plotted versus the concentration and the intercept of this regression line with the $x$-axis gave the initial analyte concentration in the sample.

\section{Method validation}

Since food supplements with certified concentrations of mycotoxins are not available, artificially fortified mycotoxin-free samples were analyzed during the development of the method as well as in the validation study to verify the recovery, trueness, precision, linearity, limits of detection and limits of quantification. The use of a triple quadrupole provides high selectivity and specificity. Two MRM-transitions were monitored, which improves specificity. For identification, the ratios of the two MRM-transitions were compared with those of the standards. The trueness was evaluated by recovery experiments. Standards were added to analyte-free samples prior to the extraction step and the spiked samples were analyzed by the standard addition method as described above. Precision of the method was studied by repeated analysis of spiked samples. The experiments were carried out at two concentrations of the analyte in the sample on the same day (intra-day precision) and on 3 consecutive days (inter-day precision). The precision was calculated as relative standard deviation (RSD) of replicate measurements. The limits of detection (LODs) and limits of 
quantification (LOQs) were determined from spiked blank samples, as the minimum detectable amount of analyte with a signal-to-noise ratio of 3 and 10, respectively. In detail, analyte-free samples were fortified with decreasing amounts of the target compounds and subsequently subjected to the whole analytical procedure. The fortification level of the target compounds was close to the assumed LODs and LOQs, on the basis of preliminary experiments. Based on these measurements, calibration curves for each analyte were established, which were then utilized to calculate the LODs and LOQs.

\section{Results and discussion}

\section{Optimization of the extraction and clean-up procedure}

The extraction procedure, as described above, was optimized after evaluating the performance of different mixtures of solvents as well as different clean-up procedures. The diversity and complexity of plant matrix do not facilitate the analysis of organic contaminants and matrix interferences must be carefully considered. Indeed, plants are rich in pigments, essential oils or fatty acids, which may interfere with mycotoxin analysis. A commercial sample of maca (Lepidium meyenii) food supplement was used as being representative of the complexity of plant matrix to set up the extraction and clean-up procedures. Besides, the structural diversity of mycotoxins leads to difficulties to recover the different types of mycotoxins during sample preparation and therefore, compromises have to be found. Different proportions of acetonitrile/water and methanol/water were frequently used to extract mycotoxins (Krska et al. 2008). Attempts to apply these solvents to food supplements resulted in the extraction of matrix components that made further clean-up difficult. The use of ethyl acetate and dichloromethane has also been reported (Delmulle et al. 2006). In this study, the best compromise for the simultaneous extraction of the different mycotoxins from food supplements was achieved using the solvent mixture ethyl acetate/formic acid $(95: 5, v / v)$, 
which proved to be more efficient than ethyl acetate alone. The latter did not allow the extraction of F-B1, F-B2, F-B3 and OTA. Alternatively, the solvent mixture ethyl acetate/ trifluoroacetic acid $(97: 3, v / v)$ was tested, and drastically improved the extraction of the fumonisins (F-B1: $59 \%$, F-B2: $55 \%$, F-B3: $61 \%$ ). However, this solvent mixture was not developed further, because it resulted in a dramatic decrease of the recovery for STERIG, AFB1, and AF-G1. Moreover, the extraction of other toxins was also generally less good.

For the extract clean-up, the use of $\mathrm{NH}_{2}$ SPE cartridges was first investigated. The results obtained showed a loss of fumonisins. Further, two adsorbents suitable for the extraction of both polar and non-polar compounds, namely Oasis HLB ${ }^{\mathrm{TM}}$ and Carbograph, were tested. The best results were obtained using Oasis $\mathrm{HLB}^{\mathrm{TM}}$ SPE cartridges. Considering the high amount of fatty matrix compounds that were co-extracted with the ethyl acetate-containing solvent, a $n$-hexane defatting step was necessary prior to SPE.

The performance of the extraction and clean-up procedure was evaluated by extraction yield experiments carried out by spiking analyte-free sample, before and after the extraction and clean-up step, and following the rest of the procedure. Calculations were performed by comparing peak areas for the same compound in samples spiked ante and post extraction and clean-up. Recovery data for different food supplements are shown in Table 2. For the different combinations of matrices and analytes, the recoveries were above $60 \%$, except for NIV, STERIG and the fumonisins. Nevertheless, low recovery was not considered to be an obstacle for a reliable determination, as the other performance data such as trueness, precision, linearity and sensitivity were good. 


\section{Validation}

When LC-MS was applied to the analysis of mycotoxins in food supplements, significant signal suppression was observed. Variations of signal suppression between different samples were also substantial. Addition of internal standard did not compensate for matrix effect differences between samples. Indeed, the special problem of matrix effects in LC-MS stems from the fact that the sample matrix may be subjected to the chromatographic separation, resulting in a different and in each case unknown matrix effect for each of the analytes in a multi-component analysis. Thus, one internal standard cannot compensate for these effects but a chemically similar and co-eluting compound is required for each analyte. An approach is the addition of isotopically labelled standard (Rychlik and Asam 2008). The use of these substances is useful for the correction of the signal deviation because they have the same chemical properties and the same retention times as the non-labelled substances. However, isotopically labelled internal standards were not available for all analytes. On the other hand, matrix-matched calibration could not be applied due to matrix differences between food supplement samples. Therefore, the standard addition was the only available method to perform correct quantitative analysis.

When using standard addition as quantification technique, to our knowledge, no guidelines for method validation are available. Nevertheless, it remains necessary to investigate specificity, sensitivity, linearity, trueness and precision.

The specificity of the method was improved by monitoring two MRM-transitions for each target mycotoxin. Deviations of relative ion intensities for the MRM-transitions were not greater than the maximum permitted tolerances (Commission Decision 657/2002). According 
to the European Commission Decision 657/2002, the relative ion intensities expressed as a percentage of the intensity of the most abundant ion must correspond to those of the ions in the solutions of standards, with a maximum permitted deviations of $20 \%$ (relative ion intensity > 50\%), 25\% (relative ion intensity: 21-50\%), 30\% (relative ion intensity: 11-20\%), $50 \%$ (relative ion intensity $\leq 10 \%$ ). In addition, relative retention times with regard to the internal standard were below the maximum permitted deviation of $2.5 \%$. The trueness of the method was assessed as described above. The results are summarized in Table 3 and are in good agreement with the Commission Decision 657/2002 performance criteria for quantitative methods of analysis. All trueness values are within 80-110\%. The linearity data of the standard addition calibration plots are also shown in Table 3. The calibration curves obtained revealed good linearity for most of analytes, with correlation coefficients $R^{2}$ not lower than 0.98 for BEAU and STERIG and not lower than 0.99 for all the other analytes. The results of the method precision are shown in Table 4 and are in agreement with the recommended acceptable RSD values for repeatability for different analyte concentrations (European Commission Regulation 2006/401/EC). LOD and LOQ data are reported in Table 5. The LODs were in the range $0.3-10 \mathrm{ng} / \mathrm{g}$, except for NIV (30 ng/g), F-X (25 ng/g) and AME (30 ng/g). The European Commission has established regulatory limits for mycotoxins published in Commission Regulation (EC) No 1881/2006 of 19 December 2006 setting maximum levels for certain contaminants in some foodstuffs. Commission Regulation (EC) No 1126/2007 of 28 September 2007 amends Regulation (EC) No 1881/2006 setting maximum levels for Fusarium toxins in maize and maize products. Although no limits were set for mycotoxins in food supplements, results presented in Table 5 indicated that the developed method was suitable for the detection of mycotoxins according to the existing European regulations.

\section{Mycotoxin analysis in commercial food supplement samples}


The optimized and validated method was used to assess mycotoxins in different food supplement samples. In total, 62 samples belonging to 6 different types of food supplements namely maca, soy isoflavones, St John's wort, garlic, ginkgo biloba and black radish were analyzed. Due to different matrix effects observed in different food supplement samples, the standard addition technique was applied to perform accurate quantification.

In 56 out of 62 samples analyzed, none of the 23 mycotoxins investigated was detected. Positive samples (Table 6) contained at least one of the toxins F-B1, F-B2, F-B3 and OTA. The European Commission has established maximum levels for mycotoxins in certain contaminants in foodstuffs; no regulatory limits were set for mycotoxins in food supplements. Therefore, limits for other foodstuffs were considered as an indication. In 2 samples, OTA was found at a level above $2 \mathrm{ng} / \mathrm{g}$ (maximum level of OTA in wine and grape juice). The levels of F-B1, F-B2 and F-B3 were largely below $800 \mathrm{ng} / \mathrm{g}$ (maximum level for the sum of F-B1 and F-B2 in breakfast cereals) in all positive samples.

In order to evaluate health hazard due to the intake of the contaminated food supplements, a preliminary risk assessment was performed for OTA, on the sample with the highest level of contamination, namely sample $\mathrm{N}^{\circ} 22$ (OTA, $6 \mathrm{ng} / \mathrm{g}$ ). The European Food Safety Authority (EFSA) estimated the Tolerable Weekly Intake (TWI) at $120 \mathrm{ng}$ OTA/kg b.w. per week, which corresponds to a Tolerable Daily Intake (TDI) of $17.14 \mathrm{ng} / \mathrm{kg}$ b.w. per day. This means less than $1200 \mathrm{ng}$ OTA per day for an adult of $70 \mathrm{~kg}$. Considering the recommendations provided by the supplier in terms of daily consumption $(\sim 1.5 \mathrm{~g})$, OTA intake from sample $\mathrm{N}^{\circ}$ 22 would be 9 ng per day, which is $0.75 \%$ of the TDI. Consequently, the risk from the occurrence of mycotoxins in the food supplements analyzed in the present study is negligible. 
However, the presence of mycotoxins in some food supplement samples indicates the need for quality control of these products.

\section{Conclusions}

An LC-MS/MS method for the simultaneous analysis of 23 mycotoxins (NIV, DON, 3ADON, 15-ADON, NEO, F-X, DAS, HT-2, T-2, AF-B1, AF-B2, AF-G1, AF-G2, AOH, AME, ALT, F-B1, F-B2, F-B3, OTA, ZEN, BEAU and STERIG) was optimized and validated for food supplements. The method was successfully applied to maca, soy isoflavones, St John's wort, garlic, Ginkgo biloba and black radish samples. Due to different matrix effects observed in different food supplement samples and because labelled internal standards are not available for each individual analyte, we recommend the standard addition approach for correct quantitative analysis. This study is the first report of analysis of food supplement samples for an extended list of 23 mycotoxins, and 4 of these toxins were detected.

\section{Acknowledgment}

The authors thank the Belgian Federal Science Policy Office (BELSPO) for financial support (FOODINTER SD/AF/04A). 


\section{References}

Abbas HK, Cartwright RD, Xie W, Shier WT. 2006. Aflatoxin and fumonisin contamination of corn (maize, Zea mays) hybrids in Arkansas. Crop Prot. 25:1-9.

Abeywickrama K, Bean G. 1991. Toxigenic Aspergillus flavus and aflatoxins in Sri Lankan medicinal plan material. Mycopathologia. 113: 187-190.

Ali N, Nashim NH, Saad B, Safan K, Nakajima M, Yoshizawa T. 2005. Evaluation of a method to determine the natural occurrence of aflatoxins in commercial traditional herbal medicines from Malaysia and Indonesia. Food Chem Toxicol. 43:1763-1772.

Berthiller F, Schuhmacher R, Buttinger G, Krska R. 2005. Rapid simultaneous determination of major type A- and B-trichothecenes as well as zearalenone in maize by high performance liquid chromatography-tandem mass spectrometry. J Chromatogr A. 1062:209-216.

Betina V. 1993. Chromatography of mycotoxins: Techniques and applications. J Chromatogr Libr. 54:141-149.

Biselli S, Hartig L, Wegener H, Hummert C. 2005. Analysis of fusarium toxins using LCMS-MS: Application to various food and feed matrices. LC GC North America. 23:404-416.

Cavalière C, D’Ascenzo G, Foglia P, Pastorini E, Samperi R, Lagana A. 2005. Determination of type B trichothecenes and macrocyclic lactone mycotoxins in field contaminated maize. Food Chem. 92:559-568.

Commission Decision of 12 August 2002 implementing Council Directive 96/23/EC concerning the performance of analytical methods and the interpretation of results (2002/657/EC). 2002. Official J Euro Commun. L 221:8-36.

Delmulle B, De Saeger S, Adams A, De Kimpe N, Van Peteghem C. 2006. Rapid Commun Mass Spectrom. 20:771-776.

D'Ovidio K, Trucksess M, Weaver C, Horn E. McIntosh M, Bean G. 2006. Aflatoxins in ginseng roots. Food Addit Contam. 23:174-180.

Fink-Gremmels J. 1999. Mycotoxins: Their implications for human and animal health. Vet. Q. 21:115-120.

Fink-Gremmels J. 2008. Mycotoxins in cattle feeds and carry-over to dairy milk: a review. Food Addit Contam. 25:172-180. 
Galtier P. 1998. Biological fate of mycotoxins in animals. Revue Med Vet. 149:549-554.

Gray SL, Lackey BR, Tate PL, Riley MB, Camper ND. 2004. Mycotoxins in root extracts of american and asian Ginseng bind estrogen receptors $\alpha$ and $\beta$. Exp Biol Med. 229:560-568.

Halt M. 1998. Moulds and mycotoxins in herb tea and medicinal plants. Eur J Epidemiol. 14: 269-274.

Heber D, Lembertas A, Lu QY, Bowerman S, Co VLW. 2001. An analysis of nine proprietary Chinese red yeast rice dietary supplements: Implications of variability in chemical profile and contents. J Altern Complem Med. 7:133-139.

Hussein HS, Brasel JM. 2001. Toxicity, metabolism, and impact of mycotoxins on humans and animals. Toxicology. 167:101-134.

Kokkonen M, Jestoi M, Rizzo A. 2005. Determination of selected mycotoxins in mould cheeses with liquid chromatography coupled to tandem with mass spectrometry. Food Addit Contam. 22:449-456.

Krska R, Baumgartner S, Josephs R. 2001. The state-of-the-art- in the analysis of type A- and B-trichothecene mycotoxins in cereals. Fresen. J. Anal. Chem. 371:285-299.

Krska R, Josephs R. 2001. The state-of-the-art in the analysis of estrogenic mycotoxins in cereals. Fresenius J Anal Chem. 369:469-476.

Krska R, Schubert-Ullrich P, Molinelli A, Sulyok M, Macdonald S, Crews C. 2008. Mycotoxin analysis: an update. Food Addit Contam. 25:152-163.

Langseth W, Rundberget T. 1998. Mycotoxin production and cytotoxicity of Fusarium strains isolated from Norwegian cereals. J Chromatogr A. 815:103-113.

Martins ML, Martins HM, Bernardo F. 2001. Fumonisins B1 and B2 in black tea and medicinal plants. J Food Protect. 64:1268-1270.

Monbaliu S, Van Poucke C, Van Peteghem C, Van Poucke K, Heungens K, De Saeger S. 2009. Development of a multi-mycotoxin LC-MS/MS method for sweet pepper analysis. Rapid Commun Mass Spectrom. 23: 3-11.

Monti SM, Fogliane V, Logrieco A, Ferracane R, Ritieni A. 2000. Simultaneous determination of beauvericin, enniatins, and fusaproliferin by high performance liquid chromatography. J Agric Food Chem. 48:3317-3320. 
Nielsen KF, Thrane U. 2001. Fast methods for screening of trichothecenes in fungal cultures using gas chromatography-tandem mass spectrometry. J Chromatogr A. 929:75-87.

Omurtag GZ, Yazicioğlu D. 2004. Determination of fumonisin B1 and B2 in herbal tea and medicinal plants in Turkey by high-performance liquid chromatography. J Food Protect. 67:1782-1786.

Rizzo I, Varzavsky E, Vedoya G, Haidukowski M, Frade H, Chiale C. 1999. Mycotoxicological control on raw material and tablets of cascara sagrada (Rhamnus purshiana). Mycotoxin Research. 15:91-95.

Rizzo I, Vedoya G, Mauruto S, Haidukowski M, Varsavsky E. 2004. Assessment of toxigenic fungion Aregentinean medicinal herbs. Microbiol Res. 159:113-120.

Royer D, Humpf HU, Guy PA. 2004. Quantitative analysis of Fusarium mycotoxins in maize using accelerated solvent extraction before liquid chromatography/atmospheric pressure chemical ionization tandem mass spectrometry. Food Addit Contam. 21:678-692.

Rundberget T, Wilkins AL. 2002. Determination of Penicillium mycotoxins in foods and feeds using liquid chromatography-mass spectrometry. J Chromatogr A. 964:189-197.

Rychlik M, Asam S. 2008. Stable isotope dilution assays in mycotoxin analysis. Anal Bioanal Chem. 390:617-628.

Schwadorf K, Müller HM. 1992. Determination of $\alpha$ - and $\beta$-zearalenol and zearalenone in cereals by gas chromatography with ion-trap detection. J Chromatogr. 595:259-267.

Sewram V, Nieuwoudt TW, Marasas WFO, Shephard GS, Ritieni A. 1999. Determination of the Fusarium mycotoxins, fusaproliferin and beauvericin by high-performance liquid chromatography-electrospray ionization mass spectrometry. J Chromatogr A. 858:175-185.

Sewram V, Shephar GS, Van Der Merwe L, Jacobs TV. 2006. Mycotoxin contamination of dietary and medicinal wild plants in the Eastern Cape province of South Africa. J. Agric. Food Chem. 54:5688-5693.

Shephard GS, Thiel PG, Stockenström S, Sydenham EW. 1996. Worldwide survey of fumonisin contamination of corn and corn-based product. J AOAC Int. 79:671-687.

Shephard G.S. 1998. Chromatographic determination of the fumonisin mycotoxins. J Chromatogr. A. 815:31-39. 
Soleas GJ, Yan J, Goldberg DM. 2001. Assay of Ochratoxin A in Wine and Beer by HighPressure Liquid Chromatography Photodiode Array and Gas Chromatography Mass Selective Detection. J. Agric. Food Chem. 49:2733-2740.

Sorensen LK, Elbaek TH. 2005. Determination of mycotoxins in bovine milk by liquid chromatography tandem mass spectrometry. J Chromatogr B. 820:183-196.

Spanjer MC, Rensen PM, Scholten JM. 2008. LC-MS/MS multi-method for mycotoxins after single extraction, with validation data for peanut, pistachio, wheat, maize, cornflakes, raisins and figs. Food Addit Contam. 25:472-489.

Sulyok M, Berthiller F, Krska R, Schuhmacher R. 2006. Development and validation of a liquid chromatography/tandem mass spectrometric method for the determination of 39 mycotoxins in wheat and maize. Rapid Commun Mass Spectrom. 20:2649-2659.

Tanaka T, Yoneda A, Inoue S, Sugiura Y, Ueno Y. 2000. Simultaneous determination of trichothecene mycotoxins and zearalenone in cereals by gas chromatography-mass spectrometry. J Chromatogr A. 882:23-28.

Tassaneeyakul W, Razzazi-Fazeli E, Porasuphatana S, Bohm J. 2004. Contamination of aflatoxins in herbal medicinal products in Thailand. Mycopathologia. 158: 239-244.

Thakur RA, Smith JS. 1994. Analysis of fumonisin B1 by negative-ion thermospray mass spectrometry. Rapid Commun Mass Spectrom. 8:82-88.

Thirumala-Devi K, Mayo MA, Reddy G, Tangni EK, Larondelle Y, Reddy DV. 2001. Occurrence of ochratoxin A in black pepper, coriander, ginger and turmeric in India. Food Addit Contam. 18:830-835.

Trucksess MW, Weaver CM, Oles CJ, Rump LV, White KD, Betz JM, Rader JI. 2007. The use of multi-toxin immunoaffinity columns for determination of aflatoxins and ochratoxin a in ginseng and ginger. J AOAC Inter. 90:1042-1049.

Trucksess MW, Scott PM. 2008. Mycotoxins in botanicals and dried fruits: A review, Food Addit Contam. 25:181-192.

Valenta H. 1998. Chromatographic methods for the determination of ochratoxin A in animal and human tissues and fluids. J Chromatogr. A.815:75-92. 
Ware GM, Zhao Y, Kuan SS, Carman AS. 1999. Preparative method for isolating alphazearalenol and Zearalenone using extracting disk. J AOAC Int. 82:90-94.

Yang MH, Chen JM, Zhang XH. 2005. Immunoaffinity column clean-up and liquid chromatography with post-column derivatization for analysis of aflatoxins in traditional Chinese medicine. Chromatographia. 62:499-504.

Young JC, Lafontaine P. 1993. Detection and characterization of fumonisin mycotoxins as their methyl esters by liquid chromatography/particle-beam mass spectrometry. Rapid Commun Mass Spectrom. 7:352-359. 
Table 1 MS/MS parameters for the analysis of target analytes by MRM ESI positive ionization mode

\begin{tabular}{|c|c|c|c|c|c|}
\hline Target compounds & $\begin{array}{l}\text { Retention time } \\
\text { (min) }\end{array}$ & $\begin{array}{c}\text { Precursor ion } \\
(\mathrm{m} / \mathrm{z})\end{array}$ & Cone voltage (V) & $\begin{array}{c}\text { Product ions } \\
(\mathrm{m} / \mathrm{z})\end{array}$ & $\begin{array}{c}\text { Collision energy } \\
(\mathrm{eV})\end{array}$ \\
\hline \multirow[t]{2}{*}{ NIV } & 3.18 & $313.0[\mathrm{M}+\mathrm{H}]^{+}$ & 26 & $124.9 *$ & 12 \\
\hline & & & & 177.2 & 13 \\
\hline \multirow[t]{2}{*}{ DON } & 4.29 & $297.0[\mathrm{M}+\mathrm{H}]^{+}$ & 23 & $203.3 *$ & 10 \\
\hline & & & & 249.5 & 15 \\
\hline \multirow[t]{2}{*}{ NEO } & 5.39 & $400.1\left[\mathrm{M}+\mathrm{NH}_{4}\right]^{+}$ & 20 & $305.3 *$ & 13 \\
\hline & & & & 365.1 & 10 \\
\hline \multirow[t]{2}{*}{ F-X } & 5.26 & $355.1[\mathrm{M}+\mathrm{H}]^{+}$ & 22 & $175.3 *$ & 11 \\
\hline & & & & 247.3 & 9 \\
\hline \multirow[t]{2}{*}{ 3-ADON } & 6.47 & $339.2[\mathrm{M}+\mathrm{H}]^{+}$ & 23 & $231.2 *$ & 10 \\
\hline & & & & 203.2 & 10 \\
\hline \multirow[t]{2}{*}{ 15-ADON } & 6.49 & $339.1[\mathrm{M}+\mathrm{H}]^{+}$ & 24 & $137.1 *$ & 10 \\
\hline & & & & 321.2 & 8 \\
\hline \multirow[t]{2}{*}{ AF-G2 } & 6.99 & $331.0[\mathrm{M}+\mathrm{H}]^{+}$ & 46 & $313.1 *$ & 24 \\
\hline & & & & 245.3 & 30 \\
\hline \multirow[t]{2}{*}{ AF-G1 } & 7.31 & $328.8[\mathrm{M}+\mathrm{H}]^{+}$ & 43 & $311.2 *$ & 25 \\
\hline & & & & 243.4 & 20 \\
\hline \multirow[t]{2}{*}{ AF-B2 } & 7.68 & $315.0[\mathrm{M}+\mathrm{H}]^{+}$ & 50 & $287.3 *$ & 25 \\
\hline & & & & 259.4 & 29 \\
\hline \multirow[t]{2}{*}{ AF-B1 } & 7.98 & $313.0[\mathrm{M}+\mathrm{H}]^{+}$ & 47 & $285.3 *$ & 21 \\
\hline & & & & 241.4 & 34 \\
\hline \multirow[t]{2}{*}{ DAS } & 7.97 & $384.2\left[\mathrm{M}+\mathrm{NH}_{4}\right]^{+}$ & 19 & $307.3 *$ & 11 \\
\hline & & & & 247.3 & 15 \\
\hline \multirow[t]{2}{*}{ ALT } & 8.09 & $293.1[\mathrm{M}+\mathrm{H}]^{+}$ & 24 & $257.2 *$ & 14 \\
\hline & & & & 275.2 & 10 \\
\hline \multirow[t]{2}{*}{ FB-1 } & 9.56 & $722.5[\mathrm{M}+\mathrm{H}]^{+}$ & 51 & $334.4 *$ & 37 \\
\hline & & & & 352.3 & 36 \\
\hline \multirow[t]{2}{*}{ HT-2 } & 9.26 & $441.9\left[\mathrm{M}+\mathrm{NH}_{4}\right]^{+}$ & 16 & $263.2 *$ & 13 \\
\hline & & & & 215.3 & 12 \\
\hline \multirow[t]{2}{*}{$\mathrm{AOH}$} & 10.02 & $259.1[\mathrm{M}+\mathrm{H}]^{+}$ & 53 & $185.2 *$ & 30 \\
\hline & & & & 213.1 & 25 \\
\hline \multirow[t]{2}{*}{$\mathrm{T}-2$} & 10.17 & $484.3\left[\mathrm{M}+\mathrm{NH}_{4}\right]^{+}$ & 12 & $305.2 *$ & 12 \\
\hline & & & & 245.2 & 12 \\
\hline \multirow[t]{2}{*}{ FB-3 } & 10.89 & $706.4[\mathrm{M}+\mathrm{H}]^{+}$ & 51 & $336.3 *$ & 35 \\
\hline & & & & 354.0 & 29 \\
\hline \multirow[t]{2}{*}{ OTA } & 11.27 & $404.0[\mathrm{M}+\mathrm{H}]^{+}$ & 24 & $239.1 *$ & 22 \\
\hline & & & & 358.1 & 14 \\
\hline \multirow[t]{2}{*}{ ZEN } & 11.66 & $319.2[\mathrm{M}+\mathrm{H}]^{+}$ & 25 & $185.4 *$ & 25 \\
\hline & & & & 283.3 & 13 \\
\hline \multirow[t]{2}{*}{ FB-2 } & 12.30 & $706.4[\mathrm{M}+\mathrm{H}]^{+}$ & 51 & $336.3 *$ & 35 \\
\hline & & & & 318.0 & 38 \\
\hline \multirow[t]{2}{*}{ STERIG } & 11.73 & $325.0[\mathrm{M}+\mathrm{H}]^{+}$ & 44 & $310.2 *$ & 35 \\
\hline & & & & 281.3 & 25 \\
\hline \multirow[t]{2}{*}{ AME } & 12.75 & $273.0[\mathrm{M}+\mathrm{H}]^{+}$ & 54 & $199.2 *$ & 26 \\
\hline & & & & 258.1 & 25 \\
\hline BEAU & 13.13 & $801.3\left[\mathrm{M}+\mathrm{NH}_{4}\right]^{+}$ & 32 & $244.3 *$ & 30 \\
\hline & & & & 262.4 & 30 \\
\hline ZAN & 11.36 & $321.2[\mathrm{M}+\mathrm{H}]^{+}$ & 27 & $303.2 *$ & 14 \\
\hline & & & & 189.2 & 21 \\
\hline
\end{tabular}

* Most abundant product ion 
Table 2 Recoveries obtained for the target analytes in different food supplements at two spiking levels

\begin{tabular}{|c|c|c|c|c|c|c|c|}
\hline \multirow{2}{*}{ Compounds } & \multirow{2}{*}{$\begin{array}{l}\text { Level } \\
\text { (ng/g) }\end{array}$} & \multicolumn{6}{|c|}{ Percent recovery $((\mathrm{RSD} \%), n=5)$} \\
\hline & & Maca & Soy isoflavones & Garlic & Black radish & St John's Wort & Ginkgo biloba \\
\hline \multirow[t]{2}{*}{ NIV } & 60 & $39(14)$ & $47(10)$ & $38(11)$ & $49(13)$ & $37(15)$ & $41(12)$ \\
\hline & 240 & $36(9)$ & $45(8)$ & $37(9)$ & $49(10)$ & $36(9)$ & $42(11)$ \\
\hline \multirow{2}{*}{ DON } & 40 & $65(8)$ & $72(9)$ & $66(13)$ & $71(10)$ & $68(12)$ & $66(9)$ \\
\hline & 160 & $66(6)$ & $71(6)$ & $65(9)$ & $70(8)$ & $67(7)$ & $67(7)$ \\
\hline \multirow[t]{2}{*}{ NEO } & 20 & $64(8)$ & $72(10)$ & $68(10)$ & $69(13)$ & $71(11)$ & $66(12)$ \\
\hline & 80 & $62(6)$ & $74(8)$ & $67(9)$ & $69(8)$ & $70(7)$ & $67(9)$ \\
\hline \multirow[t]{2}{*}{ F-X } & 50 & $66(12)$ & $73(10)$ & $75(16)$ & $72(10)$ & $69(13)$ & $71(11)$ \\
\hline & 200 & $68(11)$ & $72(7)$ & $75(8)$ & $73(8)$ & $68(9)$ & $72(9)$ \\
\hline \multirow[t]{2}{*}{ 3-ADON } & 60 & $60(9)$ & $66(9)$ & $64(13)$ & $68(11)$ & $65(10)$ & $63(11)$ \\
\hline & 240 & $62(7)$ & $65(6)$ & $64(8)$ & $69(8)$ & $64(7)$ & $63(9)$ \\
\hline \multirow[t]{2}{*}{ 15-ADON } & 60 & $70(11)$ & $73(9)$ & $73(10)$ & $72(10)$ & 69 (11) & 69 (12) \\
\hline & 240 & $73(7)$ & $72(6)$ & $72(8)$ & $72(8)$ & $68(9)$ & $70(9)$ \\
\hline \multirow[t]{2}{*}{ AF-G2 } & 8 & $61(12)$ & 75 (11) & $73(15)$ & 67 (13) & $73(15)$ & 64 (12) \\
\hline & 32 & $63(8)$ & $76(9)$ & $74(10)$ & $65(9)$ & $74(10)$ & $65(9)$ \\
\hline \multirow[t]{2}{*}{ AF-G1 } & 8 & $61(11)$ & $76(12)$ & $61(15)$ & $68(8)$ & $66(15)$ & 69 (11) \\
\hline & 32 & $60(9)$ & 77 (7) & $61(9)$ & $69(7)$ & 67 (11) & $68(8)$ \\
\hline \multirow{2}{*}{ AF-B2 } & 8 & $72(13)$ & $71(8)$ & $65(16)$ & $69(12)$ & $67(14)$ & 70 (13) \\
\hline & 32 & $73(9)$ & $70(6)$ & $65(10)$ & $68(8)$ & $68(9)$ & $71(7)$ \\
\hline \multirow[t]{2}{*}{ AF-B1 } & 8 & $70(13)$ & $85(10)$ & $74(16)$ & $71(14)$ & $74(13)$ & $72(14)$ \\
\hline & 32 & $68(8)$ & $83(8)$ & $73(8)$ & $72(10)$ & $74(8)$ & $73(10)$ \\
\hline \multirow[t]{2}{*}{ DAS } & 4 & $87(10)$ & $87(8)$ & $89(9)$ & $90(9)$ & $89(10)$ & $86(9)$ \\
\hline & 16 & $86(7)$ & $89(5)$ & $88(6)$ & $90(5)$ & $90(6)$ & 87 (7) \\
\hline \multirow[t]{2}{*}{ ALT } & 24 & $77(8)$ & $81(9)$ & $84(12)$ & $76(13)$ & $80(10)$ & 78 (11) \\
\hline & 96 & $78(6)$ & $81(6)$ & $84(8)$ & 77 (7) & $79(8)$ & $79(9)$ \\
\hline \multirow[t]{2}{*}{ FB-1 } & 12 & $35(10)$ & $28(9)$ & $35(12)$ & 30 (13) & 35 (12) & $32(11)$ \\
\hline & 48 & $36(8)$ & $28(6)$ & $35(9)$ & $29(7)$ & $34(9)$ & $31(8)$ \\
\hline \multirow[t]{2}{*}{ HT-2 } & 12 & $82(10)$ & $91(9)$ & $96(13)$ & $93(9)$ & $86(10)$ & $84(9)$ \\
\hline & 48 & $81(7)$ & $92(6)$ & $96(8)$ & $92(7)$ & $87(7)$ & $84(6)$ \\
\hline \multirow[t]{2}{*}{$\mathrm{AOH}$} & 50 & 89 (13) & $88(10)$ & $86(11)$ & $82(15)$ & $84(11)$ & $86(13)$ \\
\hline & 200 & $87(7)$ & 87 (9) & $85(6)$ & $83(7)$ & $83(7)$ & $86(8)$ \\
\hline \multirow[t]{2}{*}{$\mathrm{T}-2$} & 20 & $94(8)$ & $92(11)$ & $91(12)$ & $93(12)$ & $94(9)$ & $92(10)$ \\
\hline & 80 & $96(5)$ & $94(8)$ & $91(9)$ & $94(7)$ & $95(6)$ & $93(7)$ \\
\hline \multirow[t]{2}{*}{ FB-3 } & 12 & $33(11)$ & $34(10)$ & $29(14)$ & $32(13)$ & $30(13)$ & 32 (14) \\
\hline & 48 & $34(8)$ & $34(8)$ & $30(11)$ & $30(8)$ & $29(10)$ & $32(8)$ \\
\hline \multirow[t]{2}{*}{ OTA } & 4 & 87 (9) & $89(10)$ & $90(10)$ & $92(11)$ & $89(10)$ & $88(9)$ \\
\hline & 16 & $87(6)$ & $90(7)$ & $88(7)$ & $92(7)$ & $88(8)$ & $89(6)$ \\
\hline ZEN & 40 & $94(8)$ & $92(7)$ & $96(8)$ & $94(10)$ & $93(11)$ & $95(11)$ \\
\hline & 160 & $94(8)$ & $93(6)$ & $95(7)$ & $95(6)$ & $94(9)$ & $96(8)$ \\
\hline FB-2 & 4 & $32(11)$ & $35(15)$ & $28(14)$ & $31(12)$ & 29 (13) & $26(12)$ \\
\hline & 16 & $30(9)$ & $33(8)$ & $28(10)$ & $30(9)$ & $29(8)$ & $27(10)$ \\
\hline STERIG & 20 & $41(20)$ & $45(18)$ & $39(21)$ & $40(18)$ & $42(20)$ & $43(17)$ \\
\hline & 80 & 44 (13) & $44(12)$ & $35(15)$ & $38(10)$ & $41(14)$ & $42(13)$ \\
\hline AME & 60 & $69(12)$ & $71(13)$ & 75 (14) & $72(14)$ & $74(12)$ & 75 (13) \\
\hline & 240 & $71(6)$ & $71(9)$ & 77 (7) & $73(8)$ & $74(9)$ & $76(10)$ \\
\hline BEAU & 20 & $60(17)$ & $70(15)$ & $63(15)$ & $66(17)$ & $62(14)$ & $62(15)$ \\
\hline & 80 & $61(10)$ & $69(9)$ & $61(11)$ & $65(9)$ & $61(11)$ & $63(10)$ \\
\hline
\end{tabular}


Table 3 Trueness and standard addition calibration data

\begin{tabular}{|c|c|c|c|c|}
\hline \multirow{2}{*}{ Compound } & \multirow{2}{*}{$\begin{array}{l}\text { Level of spiking } \\
\text { (ng/g) }\end{array}$} & \multirow{2}{*}{ Recovery $((\operatorname{RSD} \%), n=5)$} & \multicolumn{2}{|c|}{ Standard addition calibration } \\
\hline & & & Regression equation & $\mathbf{R}^{2}$ \\
\hline NIV & 30 & $102(19)$ & $y=0.0053 x+0.1627$ & 0,989 \\
\hline DON & 20 & $95(12)$ & $y=0.0286 x+0.5440$ & 0.991 \\
\hline NEO & 10 & $97(10)$ & $y=0.0213 x+0.2064$ & 0.992 \\
\hline $\mathrm{F}-\mathrm{X}$ & 25 & $90(14)$ & $y=0.0037 x+0.0831$ & 0.990 \\
\hline 3-ADON & 30 & $91(9)$ & $y=0.0332 x+0.9084$ & 0.993 \\
\hline 15-ADON & 30 & $91(10)$ & $y=0.0606 x+1.6569$ & 0.992 \\
\hline AF-G2 & 2 & $94(18)$ & $y=0.0087 x+0.0163$ & 0.990 \\
\hline AF-G1 & 2 & $92(19)$ & $y=0.0108 x+0.0201$ & 0.990 \\
\hline AF-B2 & 2 & $96(16)$ & $y=0.0116 x+0.0111$ & 0.991 \\
\hline ALT & 6 & $89(8)$ & $y=0.0417 x+0.2224$ & 0.994 \\
\hline AF-B1 & 2 & $97(17)$ & $y=0.0144 x+0.0282$ & 0.992 \\
\hline DAS & 1 & $103(10)$ & $y=0.0251 x+0.0258$ & 0.997 \\
\hline $\mathrm{AOH}$ & 25 & $88(13)$ & $y=0.0298 x+0.6561$ & 0.989 \\
\hline HT-2 & 3 & $93(10)$ & $y=0.0060 x+0.0167$ & 0.997 \\
\hline FB-1 & 3 & $96(9)$ & $y=0.0657 x+0.1893$ & 0.992 \\
\hline $\mathrm{T}-2$ & 10 & $101(11)$ & $\mathrm{y}=0.2419 \mathrm{x}+2.4434$ & 0.996 \\
\hline FB-3 & 3 & $89(9)$ & $y=0.1437 x+0.3837$ & 0.992 \\
\hline OTA & 1 & $92(13)$ & $y=0.0618 x+0.0569$ & 0.994 \\
\hline ZEN & 20 & $98(11)$ & $y=0.0814 x+1.5953$ & 0.994 \\
\hline FB-2 & 1 & $95(12)$ & $y=0.5554 x+0.5276$ & 0.992 \\
\hline AME & 30 & $85(15)$ & $y=0.0094 x+0.2406$ & 0.989 \\
\hline BEAU & 10 & 109 (19) & $y=0.0022 x+0.0244$ & 0.980 \\
\hline STERIG & 10 & $106(17)$ & $y=0.0094 x+0.0993$ & 0.982 \\
\hline
\end{tabular}


Table 4 Precision data

\begin{tabular}{|c|c|c|c|c|c|c|c|c|c|}
\hline \multirow{3}{*}{\multicolumn{2}{|c|}{ 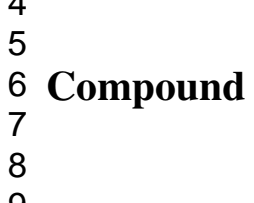 }} & \multicolumn{4}{|c|}{ Intra-day precision } & \multicolumn{4}{|c|}{ Inter-day precision } \\
\hline & & \multicolumn{2}{|c|}{ Low level } & \multicolumn{2}{|c|}{ High level } & \multicolumn{2}{|c|}{ Low level } & \multicolumn{2}{|c|}{ High level } \\
\hline & & Level (ng/g) & $\begin{array}{l}\mathrm{RSD}, \% \\
(\mathrm{n}=6)\end{array}$ & Level (ng/g) & $\begin{array}{l}\mathrm{RSD}, \% \\
(\mathrm{n}=6)\end{array}$ & Level (ng/g) & $\begin{array}{c}\mathrm{RSD}, \% \\
(\mathrm{n}=18)\end{array}$ & Level (ng/g) & $\begin{array}{c}\mathrm{RSD}, \% \\
(\mathrm{n}=18)\end{array}$ \\
\hline $\begin{array}{l}9 \\
10\end{array}$ & NIV & 60 & 14 & 240 & 8 & 60 & 16 & 240 & 10 \\
\hline 11 & DON & 40 & 8 & 160 & 7 & 40 & 12 & 160 & 10 \\
\hline $\begin{array}{l}12 \\
12\end{array}$ & NEO & 20 & 8 & 80 & 6 & 20 & 10 & 80 & 9 \\
\hline $\begin{array}{l}13 \\
14\end{array}$ & $\mathrm{~F}-\mathrm{X}$ & 50 & 12 & 200 & 9 & 50 & 18 & 200 & 13 \\
\hline 15 & 3-ADON & 60 & 9 & 240 & 6 & 60 & 12 & 240 & 10 \\
\hline $\begin{array}{l}16 \\
17\end{array}$ & 15-ADON & 60 & 10 & 240 & 6 & 60 & 12 & 240 & 9 \\
\hline 18 & AF-G2 & 8 & 12 & 32 & 8 & 8 & 14 & 32 & 12 \\
\hline 19 & AF-G1 & 8 & 12 & 32 & 8 & 8 & 16 & 32 & 11 \\
\hline 20 & AF-B2 & 8 & 13 & 32 & 10 & 8 & 17 & 32 & 13 \\
\hline 22 & ALT & 24 & 8 & 96 & 6 & 24 & 11 & 96 & 8 \\
\hline 23 & AF-B1 & 8 & 14 & 32 & 7 & 8 & 17 & 32 & 12 \\
\hline $\begin{array}{l}24 \\
25\end{array}$ & DAS & 4 & 11 & 16 & 7 & 4 & 14 & 16 & 10 \\
\hline 26 & $\mathrm{AOH}$ & 50 & 12 & 200 & 7 & 50 & 18 & 200 & 13 \\
\hline 27 & HT-2 & 12 & 11 & 48 & 8 & 12 & 17 & 48 & 12 \\
\hline $\begin{array}{l}28 \\
29\end{array}$ & FB-1 & 12 & 11 & 48 & 9 & 12 & 13 & 48 & 11 \\
\hline 30 & $\mathrm{~T}-2$ & 20 & 8 & 80 & 5 & 20 & 10 & 80 & 8 \\
\hline 31 & FB-3 & 12 & 12 & 48 & 8 & 12 & 14 & 48 & 10 \\
\hline 33 & OTA & 4 & 9 & 16 & 7 & 4 & 11 & 16 & 9 \\
\hline 34 & $\mathrm{ZEN}$ & 40 & 9 & 160 & 5 & 40 & 12 & 160 & 9 \\
\hline 35 & FB-2 & 4 & 12 & 16 & 9 & 4 & 14 & 16 & 11 \\
\hline $\begin{array}{l}36 \\
37\end{array}$ & $\mathrm{AME}$ & 60 & 12 & 240 & 6 & 60 & 14 & 240 & 10 \\
\hline 38 & BEAU & 20 & 17 & 80 & 14 & 20 & 21 & 80 & 17 \\
\hline 39 & STERIG & 20 & 20 & 80 & 13 & 20 & 22 & 80 & 16 \\
\hline
\end{tabular}


Table 5 Method limits of detection and quantification

\begin{tabular}{|c|c|c|}
\hline Compound & LOD (ng/g) & LOQ (ng/g) \\
\hline NIV & 30 & 100 \\
\hline DON & 6 & 20 \\
\hline NEO & 3 & 10 \\
\hline $\mathrm{F}-\mathrm{X}$ & 25 & 75 \\
\hline 3-ADON & 10 & 30 \\
\hline 15-ADON & 10 & 30 \\
\hline AF-G2 & 2 & 6 \\
\hline AF-G1 & 2 & 6 \\
\hline AF-B2 & 2 & 6 \\
\hline ALT & 2 & 6 \\
\hline AF-B1 & 2 & 6 \\
\hline DAS & 0.3 & 1 \\
\hline $\mathrm{AOH}$ & 8 & 25 \\
\hline HT-2 & 1 & 3 \\
\hline F-B1 & 1 & 3 \\
\hline F-B2 & 0.3 & 1 \\
\hline $\mathrm{T}-2$ & 3 & 10 \\
\hline F-B3 & 1 & 3 \\
\hline OTA & 0.3 & 1 \\
\hline ZEN & 6 & 20 \\
\hline AME & 30 & 100 \\
\hline BEAU & 3 & 10 \\
\hline STERIG & 3 & 10 \\
\hline
\end{tabular}


Table 6 Mycotoxin contamination in food supplements

\begin{tabular}{lcccccc}
\hline Product type & Sample N $^{\circ}$ & Origin & $\begin{array}{c}\text { FB1 } \\
(\mathbf{n g} / \mathbf{g})\end{array}$ & $\begin{array}{c}\text { FB2 } \\
(\mathbf{n g} / \mathbf{g})\end{array}$ & $\begin{array}{c}\text { FB3 } \\
(\mathbf{n g} / \mathbf{g})\end{array}$ & $\begin{array}{c}\text { OTA } \\
(\mathbf{n g} / \mathbf{g})\end{array}$ \\
\hline Garlic & 22 & Specialized shop & $<1$ & $<0.3$ & $<1$ & 6 \\
Maca & 29 & Drugstore & $<1$ & $<0.3$ & $<1$ & 2.5 \\
Garlic & 36 & Drugstore & 10 & 8 & 3 & 1 \\
Soy isoflavones & 41 & Drugstore & 4 & $<1$ & $<1$ & $<0.3$ \\
Black radish & 53 & Internet & 4 & 2 & $<3$ & $<0.3$ \\
Soy isoflavones & 62 & Internet & $<1$ & $<0.3$ & $<1$ & 1 \\
\hline
\end{tabular}

